\title{
Grid laser photocoagulation in the treatment of serous avascular pigment epithelial detachment in age-related macular degeneration
}

\author{
Fotocoagulação a laser em "grid" no tratamento do descolamento do epitélio pigmentado seroso \\ avascular associado à degeneração macular relacionada à idade
}

Luiz Alberto Zago Filho ${ }^{1}$, Ana Tereza Ramos Moreira ${ }^{2}$, Osvaldo Malafala ${ }^{1}$, Jorge Eduardo Fouto Matias ${ }^{1}$

\begin{abstract}
Purpose: Describe the outcomes of thermal laser photocoagulation in three cases of retinal pigment epithelium detachment associated to age-related macular degeneration.

Methods: Three patients with avascular retinal pigment epithelium detachment were treated with green diode laser photocoagulation. Mild macular grid laser application, similar to the treatment of diabetic macular edema was performed after an unsuccessful intravitreal anti-angiogenic treatment.

Results: After one year of the laser treatment, two cases reached anatomic resolution, with complete absorption of sub-epithelium serum fluid and improvement of the visual acuity. There was stability of the visual acuity and sub-epithelium fluid reduction, which, however, was partial in the third case. No complications related to the treatment occurred until the conclusion of this study.

Conclusions: Macular photocoagulation in grid pattern produced regression of avascular serous pigment epithelium detachment associated with age-related macular degeneration in a short follow-up period. Although long term prospective studies with an increased sample are necessary, it is a method that can be applied in selected patients, with absence of sub-retinal neovascularization or sub-epithelium fibrovascular component.
\end{abstract}

Keywords: Retinal pigment epithelium; Retinal drusen; Laser; Macular degeneration; Retina

\section{RESUMO}

Objetivos: Descrever os resultados da aplicação de laser térmico em três casos de descolamento do epitélio pigmentado da retina associado à degeneração macular relacionada à idade.

Métodos: Três pacientes com descolamento do epitélio pigmentado seroso avascular receberam tratamento com fotocoagulação a laser de diodo verde. A aplicação em forma de "grid" macular suave, semelhante ao tratamento de edema macular diabético foi realizada após tratamento sem sucesso com antiangiogênico intravítreo. Resultados: Após um ano da aplicação do laser, dois casos obtiveram resolução anatômica, com absorção total do fluido seroso sub-epitelial e melhora da acuidade visual. Houve estabilidade da acuidade visual e redução parcial do fluido sub-epitelial no terceiro caso. Não ocorreram complicações relacionadas ao tratamento até a conclusão deste estudo.

Conclusões: A fotocoagulação a laser em "grid" macular produziu regressão do descolamento do epitélio pigmentado seroso avascular associado à degeneração macular relacionada à idade no seguimento de curto prazo. Apesar de necessitar de estudos prospectivos de longo seguimento e com maior tamanho de amostra, trata-se de um método que pode ser aplicado em pacientes selecionados, com ausência de neovascularização sub-retiniana ou componente sub-epitelial fibrovascular.

Descritores: Epitélio pigmentado da retina; Drusas retinianas; Laser; Degeneração macular; Retina

\section{INTRODUCTION}

Age-related macular degeneration (AMD) is the leading cause of legal blindness in patients over 50 years-old in several developed countries ${ }^{(1,2)}$. The disease includes a variety of conditions and one of the most frequent features is the presence of drusen associated with changes in the retinal pigment epithelium (RPE). The presence of fluid under the pigment epithelium determines the condition of pigment epithelial detachment (PED), which can be diagnosed via retinal biomicroscopy but is better-assessed using fluorescein angiography (FA) and optical coherence tomography (OCT). These diagnostic resources allow distinction between different subgroups of AMD and approximately $10 \%$ present serous PED.

Subretinal neovascularization associated with PED is frequent and, although PEDs are clinically similar, their pathophysiology and prognosis vary depending on the subtype. In avascular serous PED, an area of dome-shaped elevation with well-defined borders reflects the relationship of firm adherence between the RPE and Bruch's membrane within its limits. Fluorescein angiography shows gradual and uniform filling of the area with pooling of dye in the late venous and tissue phases. Indocyanine green videoangiography (ICG-VA), a very useful method for the investigation of subepithelial vascular lesions, shows no signs of hyperfluorescence in any phase of the examination of the serous subtype ${ }^{(3)}$. Yanuzzi analyzed cases of early hyperfluorescence with late leakage on ICG-VA and associated them with the presence of subretinal neovascular membrane; the term vascularized PED was thus suggested ${ }^{(4)}$. These occur mainly in lesions in which there are notches in the PED's margin, sometimes with hard exudates or hemorrhages. The fibrovascular subtype presents irregularities in the elevated area of the PED and images of occult neovascularization. In FA there is early granular hyperfluorescence, impregnation of the lesion by the dye, and the presence of plaques or "hot spots" that are better detected via ICG-VA ${ }^{(5)}$. In OCT, the image of a thickened RPE by deposited material confirms the presence of exudation and neovascular activity. Drusenoid PED is the result of the clustering of soft drusen, which occurs bilaterally in approximately 91\% of cases. FA shows slow and uneven filling of the subepithelial

Submitted for publication: March 7, 2014

Accepted for publication: August 20, 2014

Study conducted as part of the the Postraduate Program in Surgical Clinic of the Federal University of Paraná, Curitiba, PR, Brazil.

Department of Surgery, Federal University of Paraná Curitiba, PR, Brazil.

2 Department of Otolaryngology-Ophthalmology, Federal University of Paraná, Curitiba, PR, Brazil.

Funding: No specific financial support was available for this study.

Disclosure of potential conflicts of interest: None of the authors have any potential conflicts of interest to disclose.

Corresponding author: Luiz Alberto Zago Filho. Rua Nilo Peçanha, 605 - Lages, SC, 88523-330 Brazil - E-mail: luzago@gmail.com 
space without leakage beyond its margins and with some pigment accumulation on its surface ${ }^{(6)}$.

Histopathological studies suggest that the damage promoted by age and the oxidative process in the Bruch's membrane, which separates the pigment epithelium from the vascularized choriocapillaris, causes its thickening and alters metabolic interactions that are dependent on hydrostatic pressure and osmolarity ${ }^{(7,8)}$. Although not very well understood, this process that occurs in the Bruch's membrane and results in lipid deposits increases its hydrophobic properties and hinders fluid exchange in the vitreous cavity towards the choriocapillaris, thus facilitating the accumulation of fluid between the layers ${ }^{(9)}$

In situations in which serous PED is associated with occult subfoveal neovascularization, there is sufficient clinical evidence that the lesion may be stabilized with anti-angiogenic treatment ${ }^{(10)}$. However, there are no defined strategies or treatment protocols for those situations in which subretinal neovascularization is not seen during ICG-VA investigation ${ }^{(11)}$. Yanuzzi addressed the treatment of serous PED by using a macular grid in cases of PED progression or persistance with reduction in visual acuity, with the exception of cases in which neovascularization was evident ${ }^{(12)}$. A study comparing the 4-year progression in patients with and without macular laser grid photocoagulation did not find a good prognosis for the treated cases. However, the study did not distinguish between serous avascular cases and cases with subretinal neovascularization, hemorrhages and hard exudates ${ }^{(13)}$.

The analysis of autofluorescence images of the cases showed clear progression of retinal and RPE damage with areas of hyper-autofluorescence and significant reduction in retinal sensitivity during PED maintenance, causing atrophy, scarring and permanent loss of vision (Figure 1 A). Avascular serous PED tends to become chronic and is a challenging condition for ophthalmologists to obtain satisfactory results, as there are no categorical procedures supported by studies.

\section{METHODS}

A prospective study was conducted between May 2009 and April 2013, after the approval by the Research Ethics Committee of the Hospital de Clínicas (Protocol CEP HC/UFPR: 045.2013). Treatment conditions, expectations and risks for patients were described in the informed consent form, signed by all patients.

Data regarding the patients treated for AMD with the anti-angiogenic agent bevacizumab (Avastin ${ }^{\circledR}$, Roche) were recorded prospectively using the SINPE ${ }^{\circledR(14)}$ software. In the initial phase of the study, the choice for the off-label use of bevacizumab was made considering its cost-benefit relation. The initial treatment protocol was intended for 58 eyes of 45 patients with a diagnosis of AMD associated or not associated with PED. The patients were informed about the procedures and subsequently received three intravitreal injections of $1.25 \mathrm{mg}$ of bevacizumab at monthly intervals. The appropriate administration technique was performed in a surgical clinic, and the treatment was maintained according to individual needs.

In this preliminary study, three patients with confirmed PED did not present improvement on lesion height or size after the first three applications of the anti-angiogenic drug. They were excluded from the initial anti-angiogenic protocol and were followed for 12 months without favorable progression or worsening of the lesion. These patients did not receive any extra treatment with anti-angiogenic drugs or oral antioxidants during this monitoring period. Given the gradual damage to the RPE, treatment with macular grid laser treatment was proposed because of the persistence of serous PED without any evidence of subretinal neovascularization.

In the initial assessment, besides the complete ophthalmological examination with visual acuity measured in logarithm of minimum angle of resolution (logMAR), FA, OCT, and ICG-VA were performed to exclude recent neovascular activity in these three cases (Figure 1 B). The characteristics of the subepithelial fluid and the height of the epithelial detachment were analyzed by time-domain optical coherence tomography (OCT Stratus, Carl Zeiss Meditec ${ }^{\circledR}$, Dublin, California, USA). All three cases showed the presence of typical serous subepithelial fluid, identified on OCT with an optically empty cavity (Figure 2 C). Any sign of fibrovascular thickening, intraretinal fluid or neovascularization would exclude the patient from the laser protocol. In addition, the exams did not show any presence of occult neovessels or "hot spots". The expected primary outcome of the study was the absorption of the fluid under the retinal pigment epithelium and anatomical improvement of the lesion, with possible improvement of visual acuity.

Laser application, using the mild macular grid technique for the treatment of diabetic macular edema, was used after pupil dilation with $1 \%$ tropicamide and topical anesthesia with $0.4 \%$ oxybuprocaine ${ }^{(15)}$. Laserburnswereinduced ( $75 \mu \mathrm{m}$ spotsize, 0.1 sduration, $80 \mathrm{~mW}$ ) $( \pm 10 \mathrm{~mW})$, using green diode laser $532 \mathrm{~nm}$ (Iridex Medical ${ }^{\circledR}$, Mountain View, California). A mild trace of tissue reaction was observed. For the treatment around the macula, 100 burns $( \pm 8)$ were induced, at a minimum distance of $1000 \mu \mathrm{m}$ from the fovea, using the contact lens Volk Area Centralis ${ }^{\circledR}$ with 2\% methylcellulose. However, laser application did not avoid points of elevation in the RPE (PED) or the presence of drusen and, unlike in the diabetic macular edema treatment protocol, the use of laser in the nasal area of the macula was avoided (Figure 3).

The three cases were sequentially reassessed using clinical and complementary tests. Monthly follow-up allowed detecting symptoms such as metamorphopsia or visual reduction, and weekly use of the Amsler grid was recommended. OCT and FA were performed at 1, 6
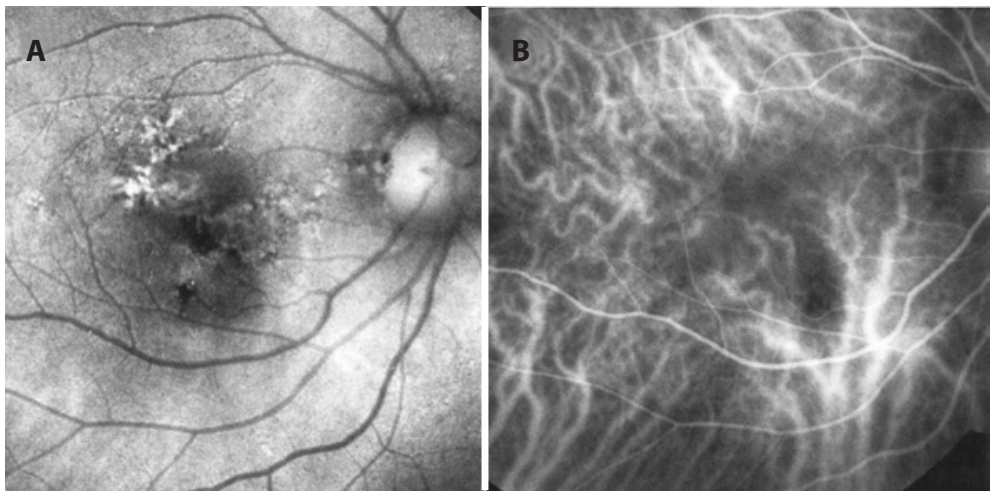

Figure 1. A) Autofluorescence showing the sequelae that are characteristic of the mobilization of the retinal pigment epithelium during maintenance therapy of chronic PED. B) Indocyanine green videoangiography of the same case showing normal choroidal circulation without neovascularization. 
and 12 months of follow-up, as well as ICG-VA in the case of suspected neovascularization. There was no need to administer anti-angiogenic drugs to the patients after they enrolled in this study protocol, and no additional laser treatment was applied.

\section{RESULTS}

Three patients with a mean age of 70.5 years (ranging from 62 to 79 years) were treated, one man and two women. The three cases presented spherical equivalent refraction close to emmetropia and had no signs of other eye diseases. The initial objective of reducing PED anatomically was detailed via OCT in all three cases. OCT showed that in cases 1 and 2 there was a significant reduction in PED height over 30 days, which suggests that the absorption of the fluid under the RPE started immediately. Figures 2 and 4 show these cases at six months: showing stable lesion on angiography, sequelae in the RPE, and small scars of photocoagulation. In these two cases, leakage or accumulation of fluid were not observed after thirty days of treatment, even in the late phases of angiography. OCT remained unchanged after one year, without any fluid under the RPE, as shown in figure $2 \mathrm{~F}$. In case 3, the first significant height reduction was observed in the OCT six months after laser treatment. Graph 1 shows the progression of PED according to the sequential measurements performed by OCT. The reduction in drusen around the macula was evident in the fundus images; they were absorbed and replaced by small foci of epithelial atrophy. However, these were not quantified or measured in this study (Figure 5). In cases 1 and 2 visual acuity showed a small improvement at the end of the study and remained stable in case 3 . Visual acuity stability was similar to that observed in other studies, where no complications were observed with any treatment modality (Table 1). There were no complaints or complications during the one-year follow-up.

\section{DISCUSSION}

The natural history of patients with chronic serous PED and AMD is associated with RPE atrophy and subretinal scarring, resulting in substantial and permanent reduced visual acuity ${ }^{(16)}$. It is suggested that older patients who exhibit larger and more elevated PEDs are at a higher risk for complications ${ }^{(17)}$. The outcome of the natural history of 46 eyes with avascular serous PED demonstrated visual acuity of $20 / 200$ or worse in $33 \%$ of the assessed cases $^{(18)}$.

The PED treatment results with anti-angiogenic drugs are variable; however, they indicate that the lesion stabilizes with the use of ranibizumab (Lucentis ${ }^{\circledast}$ ) or bevacizumab (Avastin $\left.{ }^{\circledast}\right)$, particularly in the cases with neovascular component. The initial absorption tendency of the PED was not maintained after six months of ranibizumab administration in avascular serous cases. Moreover, although the drug reduced PED height, with morphological improvement, visual stability and macular sensitivity (measured by microperimetry after one year in a small sample of cases) were not maintained ${ }^{(19)}$. The intravitreal administration of the VEGF-A inhibitor aflibercept (Eylea ${ }^{\circledR}$, Bayer) was effective and produced a quick response in three cases of elevated PED associated with neovascular AMD, despite the previous unsuccessful treatment with two other anti-angiogenic drugs $s^{(20)}$.

Some studies have shown positive results with the regular use of low-fluence photodynamic therapy with verteporfin (Visudyne ${ }^{\circledR}$, Valiant); however, these studies used a small sample size. It is sug-
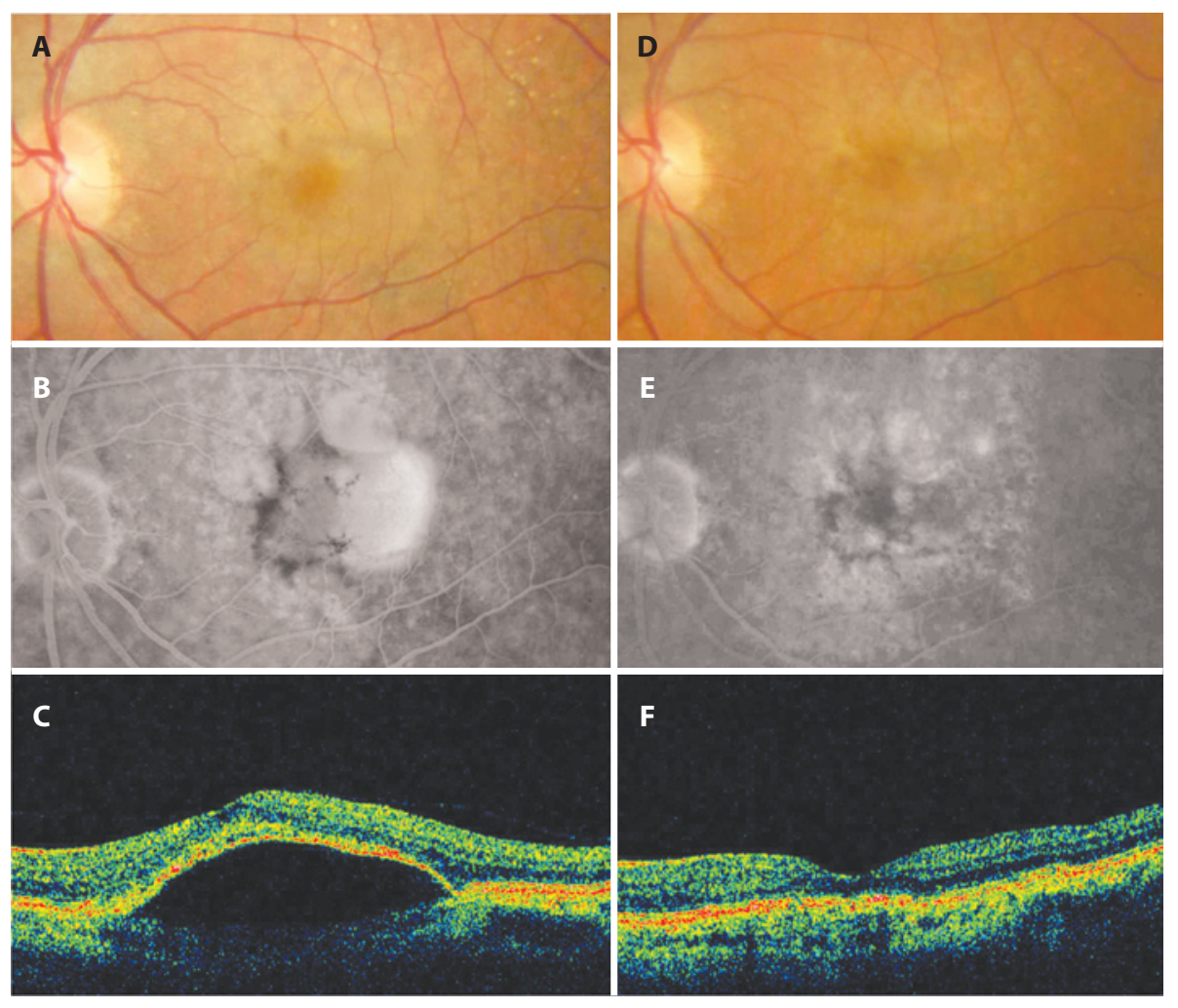

Figure 2. Case 1. Initial color retinography (A). Intermediate phase of fluorescein angiography showing dye pooling and foci of hyperplasia of the retinal pigment epithelium (B). OCT demonstrating dome-shaped PED with optically empty cavity, without signs of activity or fluid in the neurossensory retina (C). Color retinography after six months, showing flattening of the retina and reduction in the number of choroidal drusen (D). Late phase of fluorescein angiography showing spots of hyperfluorescence adjacent to the laser scars and sparse foci of atrophy of the pigment epithelium (E). OCT after one year of follow up (F). 


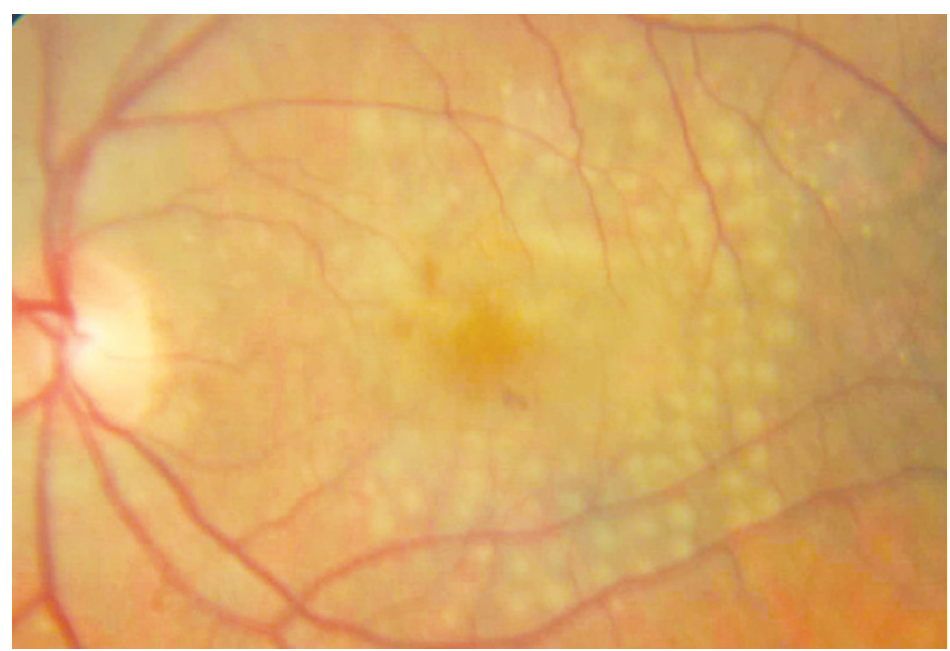

Figure 3. Color retinography performed immediately after treatment by laser photocoagulation. Mild grid technique used around the macula avoiding the papilomacular bundle.
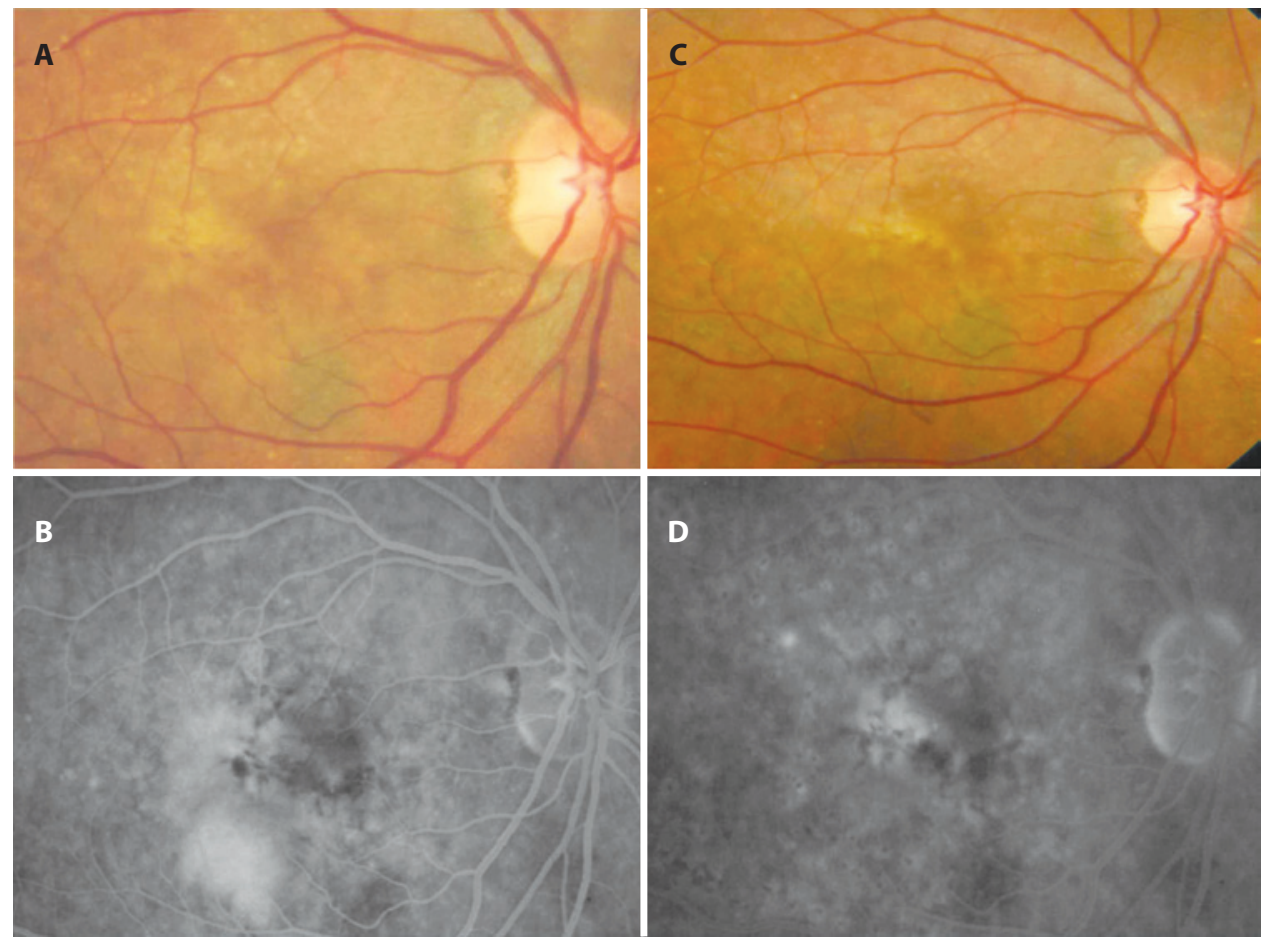

Figure 4. Case 2. Color retinogram performed before treatment showing PED with mainly atrophic diffuse changes in the pigment epithelium (A). Elevated PED in the infero-temporal sector during the venous phase fluorescein angiogram (B). Retinogram after six months of the treatment (C). Six months after treatment demonstrating sequelae in the RPE with juxtafoveal focus of dye impregnation with macular grid points are clearly visible (D).

gested that patient cases with higher dye retention on ICG-VA, and therefore with increased choroidal permeability, respond better to this treatment. This is also valid for resistant cases in which treatment can be combined with intravitreal injection of triancinolone ${ }^{(21,22)}$.

The first proposition of laser photocoagulation treatment in asymptomatic patients with PED was done by Gass $^{(23)}$. To reduce the risk of RPE tearing in the contralateral eye, patients with central drusen were treated with green or yellow laser around the macula ${ }^{(24)}$. The development of neovascular membrane was observed in patients who received higher intensity laser treatment; this process was promoted by the migration of endothelial cells of the choriocapillaris, as well as other endothelial growth factors and fibroblasts, after the tearing of Bruch's membrane ${ }^{(25)}$. Photocoagulation did not prove to be beneficial in the prevention of neovascularization in PED, when compared to the control group of another study ${ }^{(26)}$. During a report of the one-year follow-up of a case of symptomatic and progressive serous PED, the micropulse laser treatment resulted in the flattening of the lesion and visual acuity improvement ${ }^{(27)}$.

When comparing these traditional therapeutic modalities administered to 328 patients with serous PED, excluding laser photocoagulation, the best results were obtained with the anti-angiogenic drugs bevacizumab and ranibizumab. The study concluded that the 


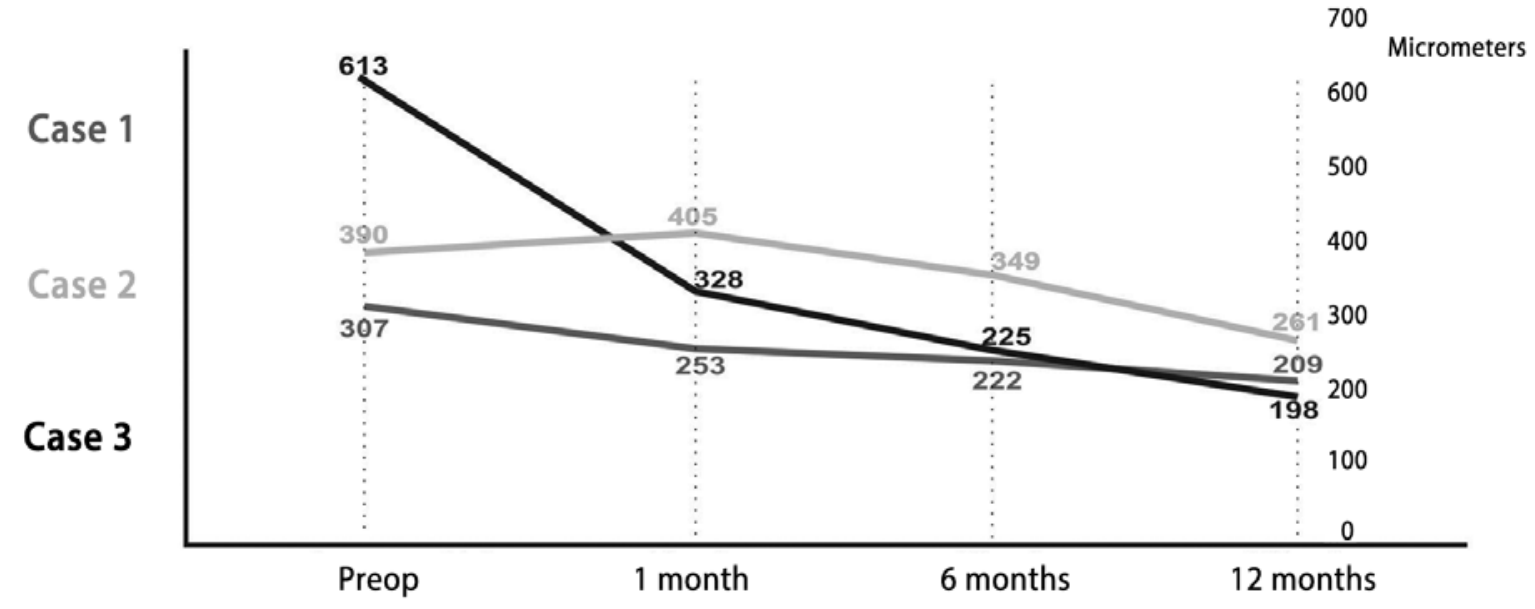

Graph 1. Height of the subretinal fluid on the PED.
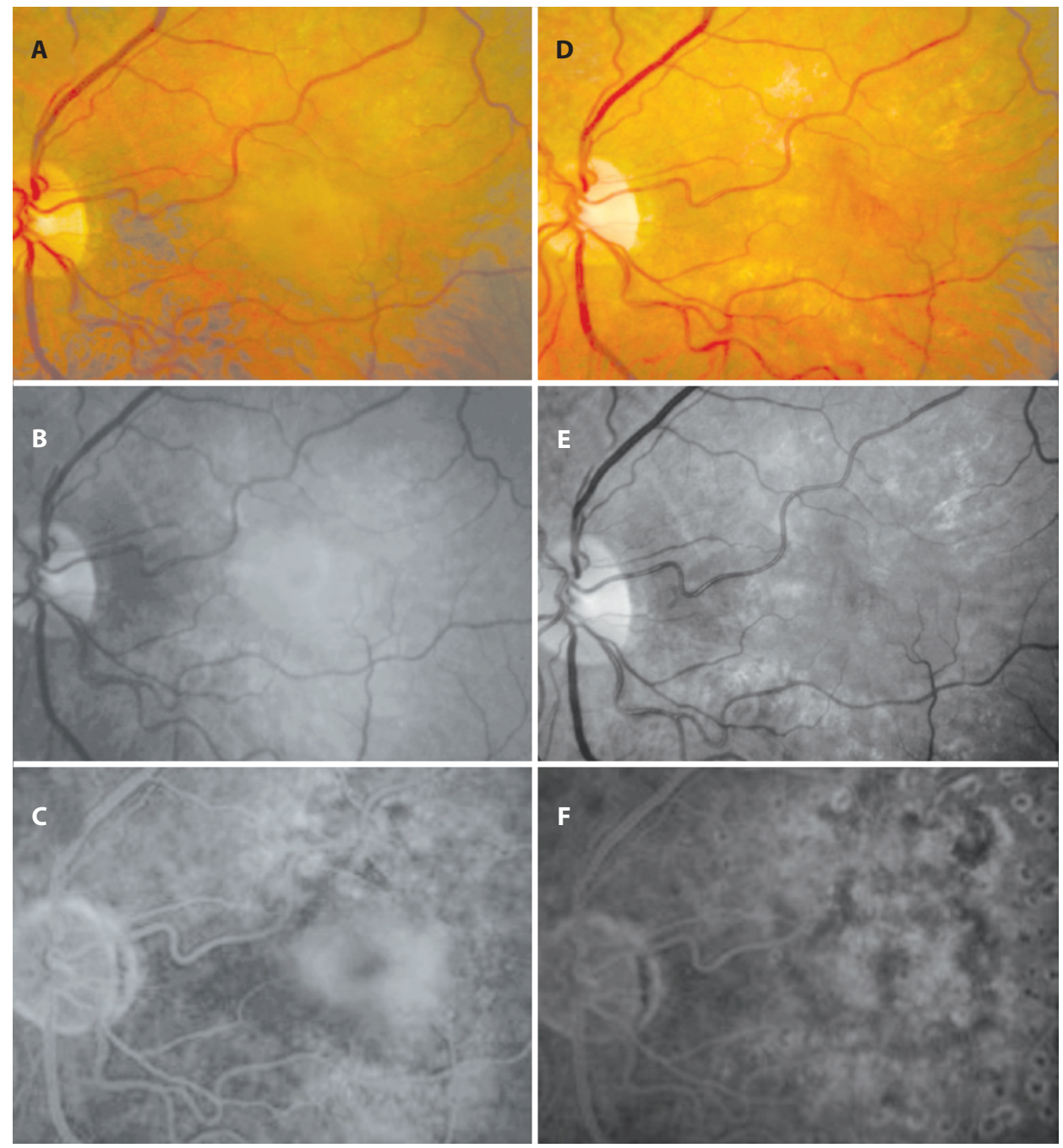

Figure 5. Case 3. Red-free color retinogram and choroidal phase of the angiography, demonstrating avascular PED with defined limits and homogeneous filling of the lesion by contrast medium (A, B and C). Exams performed six months following the laser application (D, E and F) demonstrate flatenning of the PED and the choroidal vessels, notice that fovea and the pigment epithelium are visible and there are no signs of contrast medium extravasation. Treatment sequelae with dispersion of the pigment epithelium and foci of pigmentar atrophy related to the laser marks in the associated to a small cuticilar drusen. 
Table 1. Measurements of visual acuity progression in logMAR

\begin{tabular}{lcccc}
\hline & Preop & 1 month & 6 months & 12 months \\
\hline Case 1 & 0.60 & 0.48 & 0.30 & 0.30 \\
Case 2 & 0.60 & 0.60 & 0.40 & 0.30 \\
Case 3 & 0.48 & 0.40 & 0.48 & 0.48 \\
\hline
\end{tabular}

partial flattening was more significant with these drugs than with pegaptanib or photodynamic therapy combined with intravitreal triancinolone ${ }^{(28)}$

In this study it was assumed that the neovascular or fibrovascular component exhibits a physiopathology different from that of strictly serous or avascular cases, in which there is no thickening of the tissue underlying the RPE or the presence of fluid above the pigment epithelium or inside the neurosensory retina. Based on this assumption, it was considered that treatment with mild thermal laser in the pigment epithelium stimulates epithelial cell renewal, thus favoring metabolic exchanges and promoting fluid absorption ${ }^{(29)}$.

It is suggested that the application of mild macular grid laser in cases of avascular PED reduces chronic damage in the pigment epithelium and promotes the absorption of the fluid underneath the $\mathrm{RPE}$, as mentioned in the examples above, resulting in their anatomical stability. However, care should be taken to detect complications in an early phase. In this sample of cases it was possible to closely follow the behavior of the PEDs and monitor possible complications from treatment, such as RPE tearing, development of subretinal neovascular membrane or submacular hemorrhage.

In serous PED and other subtypes, the risk of tearing in the margins of the detachment with abrupt and significant loss of vision is high. Considering that these tears occur spontaneously after anti-angiogenic treatment, photodynamic therapy and thermal laser, we opted for laser application despite the risks of this procedure ${ }^{(28)}$.

One year after treatment with mild macular grid laser there was a reduction in the number and size of drusen adjacent to the photocoagulated areas. However, a precise comparison was not possible because they were not measured or quantified before laser application. Although controversial, the treatment of drusen with laser can be applied diffusely or directly on the drusen, for them to decrease in size and number. However, there was no improvement in visual acuity during follow-ups of some cases, and therefore it is not conclusively recommended for this purpose ${ }^{(30)}$.

Considering the poor prognosis of the disease, treatment with mild macular grid laser photocoagulation is justified in some selected resistant cases of avascular PED. However, because the majority is associated with subretinal neovascularization, all suspected cases should be treated with anti-angiogenic drugs after assessment and confirmation of neovascular disease.

In these cases, a follow-up of more than one year is required to obtain long-term responses of anatomical and functional stability. Since these are the first cases described in the Brazilian literature with this clinical presentation and type of treatment, it was necessary to conduct a pilot study with a small sample size on this subject. Therefore, further prospective studies with larger sample sizes are needed to confirm the findings of this initial study.

\section{REFERENCES}

1. Klein R, Klein BE, Linton KL. Prevalence of age-related maculopathy. The Beaver Dam Eye Study. Ophthalmology.1992;99(6):933-43.

2. Jonasson F, Arnarsson A, Sasaki H, Peto T, Sasaki K, Bird AC. The prevalence of age-related maculopathy in Iceland: Reykjavik Eye Study. Arch Ophthalmol. 2003;121(3):379-85.
3. Spaide RF, Yannuzzi LA. Manifestations and pathophysiology of serous detachment of the retinal pigment epithelium and retina. In: Marmor MF, Wolfensberger TJ, editors. The retinal pigment epithelium. New York: Oxford University Press; 1998. p.439-55.

4. Yannuzzi LA, Hope-Ross M, Slakter JS, Guyer DR, Sorenson JA, Ho AC, Sperber DE, et al. Analysis of vascularized pigment epithelial detachments using indocyanine green videoangiography. Retina.1994;14(2):99-113.

5. Haddad WM, Coscas G, Soubrane G. Eligibility for treatment and angiographic features at the early stage of exudative age related macular degeneration. $\mathrm{Br} J$ Ophthalmol. 2002;86(6):663-9.

6. Roquet W, Roudot-Thoraval F, Coscas G, Soubrane G. Clinical features of drusenoid pigment epithelial detachment in age related macular degeneration. $\mathrm{Br} J$ Ophthalmol. 2004;88(5): 638-42.

7. Sheraidah G, Steinmetz R, Maguire J, Pauleikhoff D, Marshall J, Bird AC. Correlation between lipids extracted from Bruch's membrane and age. Ophthalmology. 1993; 100(1):47-51

8. Starita C, Hussain AA, Patmore A, Marshall J. Localization of the site of major resistance to fluid transport in Bruchıs membrane. Invest Ophthalmol Vis Sci.1997:38(3):762-7.

9. Bird AC. Doyne Lecture. Pathogenesis of retinal pigment epithelial detachment in the elderly; the relevance of Bruch's membrane change. Eye (Lond). 1991;5(Pt 1):1-12.

10. Chen E, Kaiser RS, Vander JF. Intravitreal bevacizumab for refractory pigment epithelial detachment with occult choroidal neovascularization in age-related macular degeneration. Retina. 2007;27(4):445-50.

11. Zayit-Soudry S, Moroz I, Loewenstein A. Retinal pigment epithelial detachment. Surv Ophthalmol. 2007;52(3):227-43.

12. Yannuzzi LA. [Retinal pigment epithelial detachment]. J Fr Ophtalmol.1989;12(11): 761-4. French.

13. Barondes MJ, Pagliarini S, Chisholm IH, Hamilton AM, Bird AC. Controlled trial of laser photocoagulation of pigment epithelial detachments in the elderly: 4 year review. Br J Ophthalmol. 1992;76(1):5-7

14. Zago Filho LA, Malafaia O, Moreira, ATR, Matias, JEF. Electronic clinical and surgical database of retina and vitreous diseases. Arq Bras Oftalmol. 2008;71(3):357-64.

15. Diabetic Retinopathy Clinical Research Network. Comparison of Modified-ETDRS and Mild Macular Grid Laser Photocoagulation Strategies for Diabetic Macular Edema. Arch Ophthalmol. 2007:125(4):469-80.

16. Casswell AG, Kohen D, Bird AC. Retinal pigment epithelial detachments in the elderly: classification and outcome. Br J Ophthalmol. 1985;69(6):397-403.

17. Bird AC, Marshall J. Retinal pigment epithelial detachments in the elderly. Trans Ophthalmol Soc UK.1986;105:674-82.

18. Poliner LS, Olk RJ, Burgess D, Gordon ME. Natural history of retinal pigment epithelia detachments in age-related macular degeneration. Ophthalmology.1986:93(5):543-51.

19. Ritter M, Bolz M, Sacu S, Deák GG, Kiss C, Pruente C, Schmidt-Erfurth UM. Effect of intravitreal ranibizumab in avascular pigment epithelial detachment. Eye(Lond). 2010; 24(6):962-8.

20. Patel KH, Chow CC, Rathod R, Mieler WF, Lim Jl, Ulanski LJ, et al. Rapid response of pigment epithelial detachments to intravitreal aflibercept in neovascular age-related macular degeneration refractory to bevacizumab and ranibizumab. Eye. 2013;27(5): 663-7.

21. Kim KS, Lee WK. Photodynamic therapy with verteporfin for avascular serous pigment epithelial detachment in elderly Koreans. Retina. 2010;30(1):93-9.

22. Goto S, Gomi F, Ueno C, Nishida K. Reduced-fluence photodynamic therapy for subfoveal serous pigment epithelial detachment with choroidal vascular hiperpermeability. Am J Ophthalmol; 2012;154(5):865-71.

23. Gass JM. Photocoagulation of macular lesions. Trans Am Acad Ophthalmol Otolaryngol. 1971; 75(3):580-608

24. Gross-Jendroska M; Owens SL; Flaxel CJ; Guymer RH; Bird AC. Prophylactic laser treatment to fellow eyes of unilateral retinal pigment epithelial tears. Am J Ophthalmol. 1998; 126(1):77-81.

25. Kaiser RS, Berger JW, Maguire MG, Ho AC, Javornik NB. Laser burn intensity and the risk for choroidal neovascularization in the CNVPT Fellow Eye Study. Arch Ophthalmol. 2001;119(6):826-32.

26. Olk RJ, Friberg TR, Stickney KL, Akduman L, Wong KL, Chen MC, et al. Therapeutic be nefits of infrared $(810 \mathrm{~nm})$ diode laser macular grid photocoagulation in prophylactic treatment of non-exudative age-related macular degeneration: two-year results of a randomized pilot study. Ophthalmology.1999;106:2082-90.

27. Battaglia-Parodi M, Sheth S, Papayannis A, Bandello F. Treatment of serous pigment epithelium detachment with subthreshold micropulse diode laser photocoagulation: a case report. Eur J Ophthalmol. 2009;19(5):887-9.

28. Lommatzsch A, Heimes B, Gutfleisch M, Spital G, Zeimer M, Pauleikhoff D. Serous pigment epithelial detachment in age-related macular degeneration: comparison of different treatments. Eye (Lond). 2009;23(12):2163-8.

29. Guymer RH, Hageman GS, Bird AC. Choroidal endothelial cell processes into Bruch's membrane. Invest Ophthalmol Vis Sci. 1997;38(Suppl):S353.

30. Laser Treatment in Fellow Eyes with Large Drusen: Updated Findings from a Pilot Randomized Clinical Trial. The Choroidal Neovascularization Prevention Trial Research Group. Ophthalmology. 2003;110(5):971-8. 